\title{
Los medios públicos frente a la desinformación. Ser y estar
}

\author{
David Corral Hernández \\ Responsable de Innovación en Contenidos de RTVE
}

\section{Referencia de este artículo}

Corral Hernández, David (2022). Los medios públicos frente a la desinformación. Ser y estar. En: adComunica. Revista Científica de Estrategias, Tendencias e Innovación en Comunicación, $\mathrm{n}^{0} 23$. Castellón de la Plana: Departamento de Ciencias de la Comunicación de la Universitat Jaume I, 331-333. DOI: http://dx.doi. org/10.6035/adcomunica.6326.

Los medios de comunicación, especialmente los públicos, tienen una gran responsabilidad y un difícil reto para poner freno y dar certezas a uno de los fenómenos pandémicos más extendidos en este siglo: la desinformación, la manipulación y la polarización. Este tipo de actividades no son en absoluto nuevas, han sido ampliamente utilizadas a lo largo de siglos y siglos por poderes políticos, económicos y militares o por fuerzas opositoras o insurgentes, entre otras muchas, para sembrar crispación, miedo e incertidumbre, causar los mayores estragos posibles y debilitar a los adversarios de una manera encubierta y económica, tanto en recursos como en vidas propias. La diferencia, en nuestro Siglo XXI, es que la mentira viaja y se propaga a velocidades hasta ahora inimaginables en un mundo cada vez más interconectado y saturado de información. Y qué nos toca a los medios públicos, ser y estar.

En un ejercicio periodístico vamos a buscar respuestas aplicando ese básico de las $6 \mathrm{~W}$ para conocer a nuestro adversario y las posibilidades que tenemos para enfrentarlo. Qué. La acción voluntaria, en distintas escalas y alcances, de difundir 
información falsa, con unos objetivos determinados que, por lo general, son perjudiciales. Cómo. Empleando todas las tecnologías disponibles y las capacidades que nos proporcionan, cada vez mayores y más asequibles, tanto para generar como para difundir bulos o bruma informativa. Quién. Es posible, aunque muy complicado atribuir el origen, en demasiadas ocasiones por la propia opacidad de las compañías digitales. Cuándo. Inesperado e imprevisible, aprovechando el efecto sorpresa y saltando cualquier medida preventiva. Dónde. Se buscan todos los canales posibles y en determinadas ocasiones son un elemento de campañas o intereses mayores, incluso elementos activos de las nuevas guerras híbridas entre grandes potencias. Por qué. Por ser fáciles de consumir, rápidas de propagar, baratas de producir y, sobre todo, por su enorme impacto en distintas sociedades (generalmente permeables al bulo), la dificultad de desmontarlas y por el escaso efecto que tiene dar verdad a la mentira una vez que ya ha causado su daño.

Los medios, como muro frente a los ataques y altavoz de información veraz y útil, tenemos obligaciones profesionales, empresariales y éticas, más aún los de carácter público. Debemos ser referentes en nuestras sociedades proporcionando información y contenidos de entretenimiento y educativos con objetividad, independencia, criterio, neutralidad, imparcialidad... Debemos primar fuentes autorizadas y acreditadas, rebatir los contenidos que resulten ser falsos o engañosos tras ser verificados y eliminar, con criterio y argumentos sólidos, los que no tengan fines lícitos o contengan mentira y desinformación. Debemos revertir el desapego que existe en muchas de nuestras sociedades recuperando a nuestros públicos y audiencias dándoles una credibilidad y confianza máxima en nuestros contenidos, actividades y fines. Debemos garantizar el acceso de cualquier persona, por cualquier medio y en cualquier lugar a información contrastada y de calidad. Debemos aprovechar la verdad para tener «rentabilidad» social e institucional, incluso económica en el caso de las empresas privadas.

Debemos usar como guía, y participar en lo posible, en las políticas y medidas impulsadas por la Unión Europea y nuestros respectivos gobiernos, un esfuerzo conjunto en el que los medios no somos ajenos y en el que debemos ser herramientas de «estado». Debemos generar nuestro marco de actuación, sea como libro blanco o manual de estilo, y que éste sea empleado por nuestros profesionales y puesto a disposición del público para su conocimiento en un claro ejercicio de transparencia. Debemos sacar el músculo, los recursos, que aún quedan en las grandes corporaciones públicas europeas y convertirlo en iniciativas como departamentos específicos, caso de Verifica en RTVE, o fortalecer alianzas como EBU/ UER, la más importante del mundo de medios de comunicación de servicio público con más de un centenar de organizaciones como partícipes. Debemos colaborar con otros medios, instituciones, etc. para hacer frente común, sumar esfuerzos, compartir conocimientos y experiencias o desarrollar, entre otras posibilidades, herramientas comunes. Debemos participar en iniciativas públicas y privadas como 
son los distintos proyectos europeos o nacionales e, incluso, poner en marcha propios. Debemos fomentar la participación e interacción de nuestras sociedades y facilitar los canales de consulta y seguimiento. Debemos educar cerrando brechas tecnológicas y de conocimiento al igual que formando para que no se comparta información no verificada que proceda de fuentes dudosas. Debemos utilizar las últimas tecnologías e innovaciones disponibles, aunque sea difícil ir por delante o a la misma velocidad que el rumor, la mentira y la desinformación, por no decir imposible, sí que debemos ir lo más cerca en su estela y nunca, nunca, quedarnos cada vez más atrás. Y en todos estos «debemos» también hay muchos "podemos», y uno fundamental es que los medios de comunicación públicos tenemos que ser y tenemos que estar para, frente a la desinformación o las injerencias externas, proteger e informar con rigor a las sociedades y democracias a las que nos debemos. 